\title{
How broad are state physician health program descriptions of physician impairment?
}

\author{
Nicholas D. Lawson 1* (D) and J. Wesley Boyd ${ }^{2}$
}

\begin{abstract}
Background: Physician health program websites in 23 states provide many descriptions of possible physician impairment. This study sought to determine whether these descriptions are so broad that almost everyone might potentially be suspected of being impaired given these descriptions.

Methods: The authors randomly selected 25 descriptions of impairment and then presented them anonymously online to members of the general population in full-time employment through Amazon's Mechanical Turk ( $N=199)$. Half of the respondents randomly received a narrowly worded version, and half received a broadly worded version of the survey questions.

Results: In the narrowly worded version of the survey, $70.9 \%$ of respondents endorsed at least one description of impairment, and 59.2\% endorsed more than one. In the broadly phrased version, 96.9\% endorsed at least one description, and $95.8 \%$ endorsed more than one. These respondents endorsed a median of 10 out of 25 (40\%) descriptions.

Conclusions: These findings call into question whether these descriptions really identify persons with poor performance or who pose a high risk of substantial, imminent harm to self or others in the workplace. They also demonstrate the extent to which these descriptions could potentially be misapplied and brand almost anyone as impaired.
\end{abstract}

Keywords: Physician impairment, Physician health program, Addiction, Substance use disorder, Coercion, Stigma, Discrimination, Physician suicide, Americans with Disabilities Act, Wellness, Well-being

\section{Background}

At present, most physician impairment policies selectively target physicians with physical and mental disorders (including substance use disorders [SUDs]) or disabilities. The American Medical Association (AMA), for example, defines physician impairment exclusively in terms of "physical, mental, or behavioral disorder[s]," [1] and mandates reporting and referrals of those suspected of being impaired to state physician health programs (PHPs) [2]. Some state laws also contain definitions [3] that state that, "impaired' or 'impairment' means the presence of the diseases of alcoholism, drug abuse, or mental illness." (We consider the term mental disorder to include SUDs for the remainder of this article unless otherwise stated.)

\footnotetext{
*Correspondence: nick.d.lawson@gmail.com; ndl30@georgetown.edu ${ }^{1}$ Georgetown University Law Center, 600 New Jersey Ave NW, Washington, DC 20001, USA
}

Full list of author information is available at the end of the article
There is very little evidence to suggest, however, that mental disorders in physicians are a meaningful cause of medical errors or preventable adverse events $[4,5]$. On the basis of empirical research, male sex appears to be a better predictor of poor performance or subsequent professional discipline than the presence of a mental disorder [6-12]. Therefore, it is not entirely clear why these policies have persisted and continue to encourage more referrals to PHPs.

State PHPs, which were originally designed primarily to treat physicians with SUDs, have expanded their outreach efforts over the years, and many provide descriptions of impairment or reasons to refer physicians to their programs that appear very broad. These descriptions are also regularly reinforced at hospital orientations, conferences, and other educational settings, which raises concerns about inappropriate targeting and mislabeling of physicians as impaired. 


\section{State PHP descriptions of impairment}

Many PHPs list, on their websites or publications otherwise, signs of behavior by physicians that are potentially concerning for either a substance use or other mental disorder. Some PHPs state that some of their descriptions of impairment are not specific and may not necessarily indicate impairment, though one [13] has described the presence of more than one sign or symptom as likely to be "a reliable indicator." All told, lists of "possible reasons for referral" or "indicators of impairment" are posted on the PHP websites of 23 states (including the District of Columbia).

Thus far, however, no empirical research has evaluated whether the presence of one, two, or more of these signs and symptoms really are reliable indicators of impairment. Given a superficial examination of these descriptions (see Additional file 1 for complete descriptions, weblinks, and other context), it is hard not to wonder whether they might actually describe behaviors or conditions exhibited by most physicians and even most members of the general public at various points in their lives. Research has yet to determine whether the published lists by PHPs are so broad that almost everyone could potentially be labeled as impaired.

Additionally, it is often unclear whether or not PHP descriptions of impairment are meant to apply to current or recent behaviors, or else to events from the distant past. Since state medical boards have been criticized for asking broad questions about a history of mental health treatments, without reference to timeframe, on medical license applications [14], this is an important consideration.

Many PHP descriptions also do not indicate whether they are meant to apply only to work settings or whether they should apply to other settings as well. Physician-employees might read one of these descriptions and assume that it applies only to behavior at work. But state PHPs and addiction providers, who sometimes justify coercive investigations into spousal and other family concerns [15], might apply them to family, community, and other domains outside the context of work.

In light of this, it cannot always be assumed that these descriptions will be applied in predicable, responsible, and appropriate ways. State medical board executive directors, for example, may have very poor knowledge regarding the laws that apply to reporting physicians for examinations and imposing disciplinary sanctions. To wit, one survey of state medical board executive directors [16] found that "thirteen of the 35 [state medical board executive directors responding to the survey, or 37\%] indicated that [they believed that] the diagnosis of mental illness by itself was sufficient for sanctioning physicians."

Given the concerns these state medical board directors' answers raise and the very broad nature of many
PHP lists of "concerning signs," we constructed an online survey with both narrowly worded and broadly phrased versions of questions for members of the general public in full-time employment to find out how many of these descriptions they would endorse. The narrowly phrased version provided a conservative estimate of respondents' endorsements, and the broadly phrased version explored the limits of just how far these descriptions could be applied and interpreted. We designed this study and constructed our survey to find out whether these descriptions might be so broad that they could potentially be misapplied and brand almost anyone as impaired.

\section{Methods}

We chose not to survey physicians but rather members of the general population in full-time employment through an online, anonymous survey using Amazon's Mechanical Turk (MTurk). While the properties and methods of research using MTurk have been studied and described in detail, surveys of physicians seemed more susceptible to response bias and more difficult to carry out in a way that would yield reliable data. We also did not think it necessary to survey physicians specifically in order to test our research hypothesis in general terms. Findings that most of the public could be described by these various signs and symptoms would still call into question whether they serve a meaningful purpose and are susceptible to being overapplied. A complete report of our methods and results in accordance with the Checklist for Reporting Results of Internet E-Surveys (CHERRIES) [17] appears as Additional file 2.

\section{Amazon's Mechanical Turk}

MTurk is a crowdsurfing market. Crowdsurfing refers to "the distribution of tasks to large groups of individuals via a flexible, open call." [18] As described by Chandler and Shapiro [17], "Online labor markets, such as [MTurk, are] designed to match people (requesters) requesting the completion of small tasks [referred to here as human intelligence tasks (HITs)] with people willing to do them (workers).... MTurk is currently the dominant crowdsourcing market used by academic researchers." According to several sources [17-20], "the data obtained [through MTurk] are at least as reliable as those obtained via traditional methods" in social science and psychology research [21], which often rely on in-person interviews and surveys.

MTurk populations are also diverse. Compared to the US population as a whole, MTurk workers are above average in cognitive aptitude, with studies reporting mixed findings on the prevalence of mental disorders [20]. They are somewhat younger, predominantly Caucasian, more educated [17, 19], and $24 \%$ report that they are 
unemployed but would prefer to be employed, compared to $8 \%$ of the US population overall [19]. Despite the fact that these respondents probably vary slightly from most in the US along these lines, anonymous online surveys are more likely to elicit honest responses than face-to-face interviews, and more likely to avoid social desirability bias [22], which results when respondents give answers to make the interviewer think positively about them.

\section{Sample}

Two hundred participants were recruited from MTurk under the restriction that they resided in the US; had a task approval rating of at least $95 \%$; had completed at least 1000 prior tasks on MTurk; and were currently employed full-time, working at least $35 \mathrm{~h}$ per week. Except for employment, these restrictions are standard for research using MTurk. These qualifications ensured consistency with prior research on MTurk, and high quality of data, since workers who start but do not complete tasks can skew survey results. MTurk participants in general are at least 18 years old.

On MTurk, workers consent to all tasks after being informed of the risks and benefits of participation, and browse tasks by title, keyword, reward, availability, and so on, to complete those that interest them. Only MTurk workers who met our prescreening requirements could view and decide whether to participate in the study. A notice was posted on MTurk requesting workers to "answer a survey about your experiences in work and other settings," were told that it would take no more than $5 \mathrm{~min}$ to complete, and that they would be paid $\$ 0.30$ electronically for their participation. Respondents were anonymized as soon as they agreed to participate and given a link to complete the survey on a separate website. Their responses were kept separate from potentially identifying information. The Institutional Review Board of Vassar College determined this study was exempt from review.

\section{Measures}

Table 1 lists PHP website descriptions of impairment that were randomly selected for the survey, with both narrow and broad versions of the wording used to construct survey items. Half of the participants were assigned to the narrowly worded version of the survey, and the rest were assigned to the broadly worded version.

The complete 571 PHP website descriptions of impairment from 23 states (including the District of Columbia) are available in Additional file 1, which also provides weblinks to these lists, the lists' titles, the descriptions, and other contextual details. The average number of descriptions provided in a typical PHP list was 24.8 (standard deviation $[\mathrm{SD}]=17.8$ ). We arranged lists alphabetically by state and used random number generator on Microsoft
Excel to pick a number from 1 to 571 in order to randomly select 25 of these descriptions for inclusion in the survey. We eliminated eight descriptions selected from random number generator because they applied only to physicians or select health care workers (e.g., "Going back into the pharmacy after hours") and could not be translated into a question for all employees in the general population. These were replaced with the first eight other descriptions that resulted from additional random number generator results.

Wording in the descriptions and additional context on the PHP website specified current time frame in only three of the 25 descriptions. For the narrowly worded version of the survey, we constructed items out of these three descriptions using present tense, and used present perfect tense (e.g., "Have you had....") for the rest. For the broadly worded version, we used present perfect tense, but added the word "ever" for all of the survey items (e.g., "Have you ever had....").

Wording and context clearly specified application to the workplace, rather than other settings, in seven of the PHP descriptions, and survey items constructed from these descriptions in both versions made clear that they applied only to work. Another PHP description ("If the resident is experiencing problems coping with patients or with the typical stress of a busy residency") did not make clear whether the "problems" affected work performance or caused "problems" only in other life contexts, and we preserved that ambiguity in both versions of the survey. Another ("Makes degrading or demeaning comments regarding patients, families, nurses, physicians, hospital personnel, or the hospital....") did not specify whether the comments were made at work or, for example, at home during discussion with spouse or family, and we did not provide additional specification in either survey version.

Fifteen of the 25 PHP descriptions contained more than one component (e.g., "Intoxicated at social events or odor of alcohol on breath while on duty"), and we broke these into separate questions for the broadly worded version. The survey also contained an additional attention check question, "Can you read this?" Respondents answering "No" to this and all other survey items were eliminated from the final results and analysis.

\section{Results}

Figure 1 displays the flow of respondents throughout the survey. Of the 230 respondents who viewed the 26 survey items (the 25 items listed in Table 1 plus the attention check), 86.5\% (199/230) completed the survey and were included in the final results. Table 2 summarizes sociodemographic characteristics of the total sample of 199 respondents. Table 3 gives the percentage of respondents in both survey versions who endorsed each 
Table 1 Wording used to survey respondents for endorsement of 25 state physician health program descriptions of impairment

\begin{tabular}{|c|c|c|c|c|c|}
\hline & \multirow[b]{2}{*}{ Description } & \multicolumn{2}{|l|}{ Specifies if } & \multirow[b]{2}{*}{ Narrow } & \multirow[b]{2}{*}{ Broad } \\
\hline & & Currently? & $\begin{array}{l}\text { At } \\
\text { work? }\end{array}$ & & \\
\hline 1 & Intimidation & No & Yes & $\begin{array}{l}\text { Have you intimidated someone } \\
\text { at work? }\end{array}$ & $\begin{array}{l}\text { Have you ever intimidated someone } \\
\text { at work? }\end{array}$ \\
\hline 2 & A deterioration in personal hygiene & No & No & $\begin{array}{l}\text { Has there been deterioration in } \\
\text { your personal hygiene? }\end{array}$ & $\begin{array}{l}\text { Has there ever been deterioration in your } \\
\text { personal hygiene? }\end{array}$ \\
\hline 3 & Constant sadness or tearfulness & No & No & $\begin{array}{l}\text { Have you been constantly sad } \\
\text { or tearful? }\end{array}$ & $\begin{array}{l}\text { - Have you ever been constantly sad? } \\
\text { - Have you ever been constantly tearful? }\end{array}$ \\
\hline 4 & Occurrence of spouse, child abuse & No & No & $\begin{array}{l}\text { Has your spouse or have your } \\
\text { children been abused? }\end{array}$ & $\begin{array}{l}\text { - Has your spouse or ex-spouse ever } \\
\text { been abused? } \\
\text { - Has your child or have your children } \\
\text { ever been abused? }\end{array}$ \\
\hline 5 & Easily agitated, irritable & No & No & $\begin{array}{l}\text { Have you been easily agitated } \\
\text { or irritable? }\end{array}$ & $\begin{array}{l}\text { - Have you ever been easily agitated? } \\
\text { - Have you ever been irritable? }\end{array}$ \\
\hline 6 & Increased patient complaints & No & Yes & $\begin{array}{l}\text { Have there been increased } \\
\text { complaints about your work } \\
\text { from clients, customers, or } \\
\text { other consumers? }\end{array}$ & $\begin{array}{l}\text { Have there ever been increased } \\
\text { complaints from client, customer, or other } \\
\text { consumer complaints about your work? }\end{array}$ \\
\hline 7 & Personality and behavioral changes & No & No & $\begin{array}{l}\text { Have you had personality and } \\
\text { behavioral changes? }\end{array}$ & $\begin{array}{l}\text { Have you ever had personality and } \\
\text { behavioral changes? }\end{array}$ \\
\hline 8 & Neglected social commitments & No & No & $\begin{array}{l}\text { Have you neglected social } \\
\text { commitments? }\end{array}$ & $\begin{array}{l}\text { Have you ever neglected social } \\
\text { commitments? }\end{array}$ \\
\hline
\end{tabular}

9 DWI arrest or DUI violations No No Have you had a DWI arrest

10 Other mental health concerns that directly impact work performance

11 Direct statements indicating distress

12 If the resident is experiencing problems coping with patients or with the typical stress of a busy residency

13 Sweating when otherwise comfortable

14 Tremors, hands shake

15 Rapid or pressured speech

16 Hospital personnel question competence and/or behavior

17 Makes degrading or demeaning comments regarding patients, families, nurses, physicians, hospital personnel, or the hospital. The physician's non-constructive criticism often works to intimidate, undermine confidence, belittle, or imply stupidity or incompetence in his or her victims.

18 Deterioration in clothing and dressing habits
No

No Has there been deterioration in your clothing and dressing habits? or DUI violation?

- Have you ever been arrested for DWI?

- Have you ever had a DUI violation?

Have you ever had mental health concerns that directly impacted your performance at work?

Have you ever made direct statements indicating distress?

- Have you ever had problems coping with clients, customers, or other consumers?

- Have you ever had problems coping with the typical stress of a busy job?

Have you ever been sweating while otherwise comfortable?

Have you ever had tremors or hands shake?

Has your speech ever been rapid?

- Have work personnel ever questioned your competence?

- Have work personnel ever questioned your behavior?

- Have you ever made demeaning or degrading statements regarding clients, customers, or consumers? dientents regarding work colleagues, or other personnel? • Have you ever made demeaning or degrading statements about work colleagues?

- Have you ever made demeaning or degrading statements about other work personnel?

- Have you ever criticized someone from your work?

Has there ever been deterioration in your clothing and dressing habits? 
Table 1 Wording used to survey respondents for endorsement of 25 state physician health program descriptions of impairment (Continued)

\begin{tabular}{|c|c|c|c|c|c|}
\hline & \multirow[b]{2}{*}{ Description } & \multicolumn{2}{|l|}{ Specifies if } & \multirow[b]{2}{*}{ Narrow } & \multirow[b]{2}{*}{ Broad } \\
\hline & & Currently? & $\begin{array}{l}\text { At } \\
\text { work? }\end{array}$ & & \\
\hline 19 & Disorganized schedule & No & Yes & $\begin{array}{l}\text { Have you had a disorganized } \\
\text { schedule at work? }\end{array}$ & $\begin{array}{l}\text { Has your work schedule ever been } \\
\text { disorganized? }\end{array}$ \\
\hline 20 & $\begin{array}{l}\text { Intoxicated at social events } \\
\text { or odor of alcohol on breath } \\
\text { while on duty }\end{array}$ & No & No & $\begin{array}{l}\text { Have you been intoxicated at } \\
\text { social events or had odor of } \\
\text { alcohol on breath while on } \\
\text { duty for work? }\end{array}$ & $\begin{array}{l}\text { - Have you ever been intoxicated at social } \\
\text { events? } \\
\text { - Have you ever had alcohol on your } \\
\text { breath while on work duty? }\end{array}$ \\
\hline 21 & Avoidant, unreliable & No & Yes & $\begin{array}{l}\text { Have you been avoidant or } \\
\text { unreliable at work? }\end{array}$ & $\begin{array}{l}\text { - Have you ever been avoidant at work? } \\
\text { - Have you ever been unreliable at work? }\end{array}$ \\
\hline 22 & Public intoxication or impairment & No & No & $\begin{array}{l}\text { Have you been intoxicated or } \\
\text { impaired at work? }\end{array}$ & $\begin{array}{l}\text { - Have you ever been intoxicated in } \\
\text { public? } \\
\text { - Have you ever been impaired in public? }\end{array}$ \\
\hline 23 & $\begin{array}{l}\text { Impaired or decreased work } \\
\text { performance }\end{array}$ & No & Yes & $\begin{array}{l}\text { Have you had impaired or } \\
\text { decreased work performance? }\end{array}$ & $\begin{array}{l}\text { - Has your work performance ever been } \\
\text { impaired? } \\
\text { - Have you ever had decreased work } \\
\text { performance? }\end{array}$ \\
\hline 24 & $\begin{array}{l}\text { Smell of alcohol on breath } \\
\text { or in perspiration }\end{array}$ & No & No & $\begin{array}{l}\text { Have you had the smell of alcohol } \\
\text { on your breath or in perspiration? }\end{array}$ & $\begin{array}{l}\text { - Have you ever had the smell of alcohol } \\
\text { on your breath? } \\
\text { - Has your perspiration ever smelled of } \\
\text { alcohol? }\end{array}$ \\
\hline 25 & Low or elevated self-esteem & No & No & $\begin{array}{l}\text { Have you had low or elevated } \\
\text { self-esteem? }\end{array}$ & $\begin{array}{l}\text { - Have you ever had low self-esteem? } \\
\text { - Have you ever had elevated self-esteem? }\end{array}$ \\
\hline
\end{tabular}

$D W I$ driving while intoxicated, $D U I$ driving under the influence

description of impairment. It also lists the mean total number of descriptions endorsed for each survey version.

In the narrow version of the survey, 73 (70.9\%) of the 103 respondents endorsed at least one description of impairment, and 61 (59.2\%) endorsed more than one. The number of descriptions endorsed for each respondent ranged from 0 to 18 (mean $=4.3, \mathrm{SD}=5.0$; median $=2)$. In the broadly worded version, 93 of 96 (96.9\%) respondents endorsed at least one description, and 92 of 96 (95.8\%) endorsed more than one. The number of descriptions endorsed ranged from 0 to 21 (mean $=9.7$, $\mathrm{SD}=5.8$; median $=10$ ).
The most commonly endorsed descriptions were "easily agitated, irritable" (42.7\% and $86.5 \%$ of respondents to narrow and broad versions of the survey, respectively) and "low or elevated self-esteem" (37.9\% and $81.3 \%)$. The least commonly endorsed were "occurrence of spouse, child abuse" (3.9\% and 12.5\%) and "DWI arrest or DUI violations" (4.9\% and $8.3 \%$ ).

\section{Discussion}

The results of this study suggest that most of the general US population in full-time employment endorse multiple descriptions of impairment on a typical PHP list. The

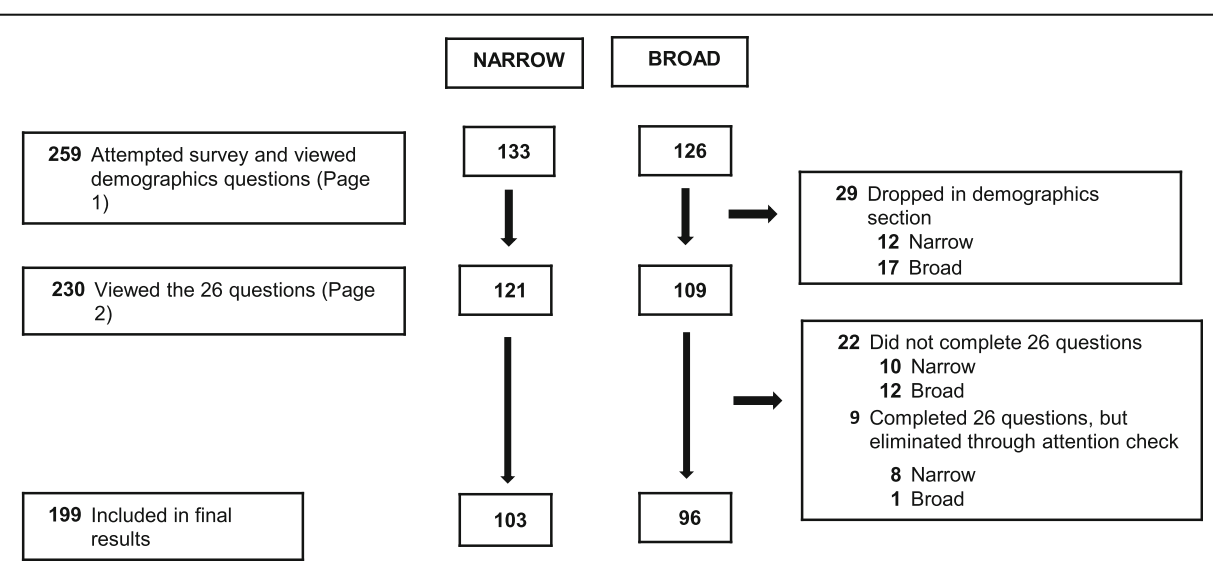

Fig. 1 Flow of respondents randomly assigned to either the narrowly worded or broadly worded survey version 
Table 2 Summary data of sociodemographic characteristics of respondents

\begin{tabular}{ll}
\hline Characteristic & {$[$ mean (SD)] or \% (n) } \\
\hline Age in yr & {$[37.6(10.6)]$} \\
Sex & \\
Male & $47.7(95)$ \\
Race/Ethnicity & \\
White & $77.9(155)$ \\
Hispanic & $5.0(10)$ \\
Non-Hispanic black & $7.5(15)$ \\
Other & $9.5(19)$ \\
Education & \\
Postgraduate degree & $24.1(48)$ \\
Bachelor's degree & $52.8(105)$ \\
High school diploma & $23.1(46)$ \\
8th grade & $0.0(0)$ \\
Employment & \\
Full-time & $100(199)$ \\
\hline
\end{tabular}

results also suggest that over $95 \%$ of the public who are employed full-time endorse multiple descriptions of impairment when broadly presented, with a median of 10 descriptions out of a typical 25 -item list. This means that a typical working member of the public will probably endorse approximately $40 \%$ (10/25) of these possible signs and symptoms of "impairment," and that therefore almost everyone could potentially be regarded as impaired by these descriptions.

Does this mean that employees all over the US are impaired, unable to complete the essential functions of their jobs, or pose a high risk of substantial imminent harm to self or others in the workplace? Of course not. But findings similar to those of this study have been interpreted in this fashion at various points in the past. The National Comorbidity Survey Replication, for example, considered a contemporary gold-standard source on prevalence, found that $44 \%$ of the US population aged $18-29$ and $37 \%$ of those $30-44$ meet criteria for a common mental disorder every year [23], and prevalence estimates for members of the medical profession also appear to be at least those of general population [24-26]. Even if it is true that $40 \%$ of physicians meet diagnostic criteria for a mental disorder every year, it simply cannot be true that $40 \%$ of physicians are impaired. Despite this obvious fact, the authors of these studies call for even more increased vigilance, identification, and treatments of physicians with suspected mental disorders [24-26].

The prevalence findings in this paper should not be interpreted as evidence in support of increased identification and evaluations of physician-employees. Our findings that PHP-described impairments are exceedingly broad call into question these descriptions' ability to identify clinicians who present a meaningful risk of harm. And they should also shine light on the considerable power that these descriptions may provide hospital managers, PHPs, and institutional leaders, who may designate almost anyone as impaired.

The consequences of such mislabeling should be considered in the context of further information regarding physicians' recourse in the event they are accused of being impaired.

\section{Recourse for physicians alleged to be impaired}

Physicians who are suspected of being impaired and instructed to undergo evaluations often have few avenues of appeal. Residents, for example, may not be able to defend themselves against accusations of impairment. We have seen firsthand how hospital administrators generally side with residency directors, so hospital administrations cannot be considered avenues of appeal. The Accreditation Council for Graduate Medical Education (ACGME) offers no protection for those in training:

[t]he ACGME does not adjudicate disputes between individual persons and residency or fellowship programs or sponsoring institutions regarding matters of admission, appointment, contract, credit, discrimination, promotion, or dismissal of faculty members, residents, or fellows [27].

Residents, who cannot practice medicine without completing a residency program, may not have the resources to hire a lawyer to protect their careers and are almost never successful in court when appealing dismissals [28-30].

Unfair or sham peer reviews of physicians alleged to be impaired have been described in many journals [31-38] but have never been studied systematically. A complaint often raised by physicians accused of being impaired is that their attempts to defend themselves or to oppose referrals to PHPs are often misrepresented as denial or lack of insight, making it harder for them to actually defend themselves [35, 39, 40]. Some leaders of PHPs, however, dispute these complaints [35] as reflective of "a small dissatisfied minority of physicians who are not able to achieve a successful return to their profession."

Such characterizations, of course, may or may not be accurate. But it is important to bear in mind that PHPs may only be aware of how those actually presenting to PHPs are being affected by their descriptions and outreach efforts. Yet these descriptions may adversely impact many other physicians who are not actually evaluated or treated at a PHP, such as those referred to other providers, and those who simply refuse to comply [5]. 
Table 3 Endorsement of 25 state physician health program descriptions of impairment in an online sample of respondents currently employed full-time

\begin{tabular}{|c|c|c|c|}
\hline \multirow{2}{*}{\multicolumn{2}{|c|}{ Description }} & \multicolumn{2}{|c|}{$\%$ Endorsing description } \\
\hline & & $\begin{array}{l}\text { Narrow } \\
(n=103)\end{array}$ & $\begin{array}{l}\text { Broad } \\
(n=96)\end{array}$ \\
\hline 1 & Intimidated someone at work & 9.7 & 19.8 \\
\hline 2 & Deterioration in personal hygiene & 9.7 & 24.0 \\
\hline 3 & Constant sadness or tearfulness & 14.6 & 41.7 \\
\hline 4 & Occurrence of spouse, child abuse & 3.9 & 12.5 \\
\hline 5 & Easily agitated, irritable & 42.7 & 86.5 \\
\hline 6 & Increased complaints from customers or clients & 4.9 & 13.5 \\
\hline 7 & Personality and behavioral changes & 19.4 & 36.5 \\
\hline 8 & Neglected social commitments & 30.1 & 47.9 \\
\hline 9 & DWI arrest or DUI violations & 4.9 & 8.3 \\
\hline 10 & Other mental health concerns that directly impact work performance & 17.5 & 24.0 \\
\hline 11 & Direct statements indicating distress & 24.3 & 35.4 \\
\hline 12 & Experiencing problems coping with customers or clients or with typical stress of a busy job & 21.4 & 62.5 \\
\hline 13 & Sweating when otherwise comfortable & 20.4 & 41.7 \\
\hline 14 & Tremors, hands shake & 17.5 & 26.0 \\
\hline 15 & Rapid speech & 15.5 & 35.4 \\
\hline 16 & Personnel question competence and/or behavior & 12.6 & 26.0 \\
\hline 17 & Makes degrading or demeaning comments at work & 15.5 & 66.7 \\
\hline 18 & Deterioration in clothing and dressing habits & 13.6 & 47.9 \\
\hline 19 & Disorganized work schedule & 23.3 & 22.9 \\
\hline 20 & Intoxicated at social events or odor of alcohol on breath while on duty & 15.5 & 50.0 \\
\hline 21 & Avoidant, unreliable & 13.6 & 42.7 \\
\hline 22 & Public intoxication or impairment & 10.7 & 53.1 \\
\hline 23 & Impaired or decreased work performance & 18.4 & 43.8 \\
\hline 24 & Smell of alcohol on breath or in perspiration & 13.6 & 64.6 \\
\hline 25 & Low or elevated self-esteem & 37.9 & 81.3 \\
\hline \multicolumn{2}{|c|}{ Mean (SD) total number of impairment descriptions endorsed } & $4.3(5.0)$ & $9.7(5.8)$ \\
\hline
\end{tabular}

$D W I$ driving while intoxicated, DUI driving under the influence

\section{The roles of key groups}

Representatives of PHPs have argued that disseminating these descriptions of reasons to refer physicians to their programs is in the best interests of the physicians themselves. This assumes, of course, that these workplace screening procedures result in more, rather than less physicians entering treatment; that these treatments are effective; that any exacerbations of stigma resulting from these screening procedures have, at worst, negligible health effects; and that employers should be involved in monitoring and treating their employees' health conditions [41]. The descriptions may also be misinterpreted by employers as reasons to remove suspected physicians from practice, request protected health information from them, or refer them for evaluations to PHPs. Such requests, if unwarranted, are illegal under the general rules and regulations of the Americans with Disabilities Act (ADA) [42].
Even though members of state medical societies, PHPs, and medical boards are likely not to be the employers of physicians who might be affected by their pronouncements, they should make every effort to ensure that these descriptions of impairment will not be applied inappropriately within the employment context. Despite this, there appears to have been almost no progress over the last 10 years in removing discriminatory questions from state medical licensure applications $[14,43]$, nor, as far as we know, any efforts to amend policies on physician impairment within the profession in order to align with the ADA, more than 27 years since it first became law.

Interrelationships among key influential groups may have something to do with the inaction on policy related to physician impairment. The AMA's policies, for example, are created by the members of its House of Delegates, most of whom are representatives of state medical societies 
[44], which generally work closely with PHPs and are sometimes (as is the case in Massachusetts) their parent organization. The AMA's policies on physician impairment were what gave rise to corresponding state laws and medical board regulations on physician impairment [45] and mandate referrals to PHPs.

Through the AMA, state medical societies have called for more research on PHPs by state medical societies $[1,2]$. To date, we do not believe the conclusions reached about PHP effectiveness in the medical literature can be fully trusted, since the overwhelming majority of research on PHP outcomes has been performed by representatives of PHPs and/or the evaluation and treatment centers where PHPs often mandate physicians seek treatment [46], and which often have significant conflicts of interest with PHPs [36, 47]. PHP research usually touts very high levels of effectiveness but generally fails to disclose potential bias by authors as well as the fact that key flaws in their study designs limit the conclusions that can reasonably be drawn from these studies [46].

At present, we do not have data about the number of physicians being mislabeled as impaired or inappropriately referred to PHPs. Some journals have published anecdotal accounts of physicians inappropriately labeled as impaired, but to our knowledge, scientific data do not exist. Despite this, we have seen dozens of instances in which physicians who have shown no signs of impairment in the workplace were mandated to undergo evaluations or monitoring with PHPs, or other providers.

We have not seen any PHP (or other professional medical group mentioned previously) post ADA rules on their websites or incorporate ADA rules into their policies. We believe that physicians ought to be aware of their employment rights under the ADA but wonder if these omissions are intentional, given that businesses and occupational health organizations have aggressively lobbied to prevent the US Equal Employment Opportunity Commission (US EEOC) from implementing additional regulations pertaining to workplace wellness programs that could reduce the incidence of prohibited medical inquiries and workplace disability discrimination $[48,49]$.

\section{Future directions}

Critics of these policies and practices have called for audits of PHPs [40, 47]; antitrust policy [50]; policies for a means of appeal of state medical board/PHP decisions [40, 47]; and revocation of the Health Care Quality Improvement Act (HCQIA) of 1986 and the Patient Safety and Quality Improvement Act of 2005 [31, 34, 35], which reduced physicians' ability to defend themselves against a hospital's peer review even more than the HCQIA. Another suggestion has been that state medical boards be replaced by a single, federal entity overseeing these issues $[50,51]$. These are all good ideas, but they might not be sufficient to address the problems discussed in this article. The persons made in charge of the federal entity, for example, could end up being be the same people in charge of state medical societies/medical boards/PHPs right now. Calls for these reforms have also so far not been successful.

In our view, these problems call for the involvement of entities working well outside the healthcare professions, as health lawyers may not be aware of the ADA's rules or may significantly downplay ADA regulations while trumpeting the guidelines provided by professional medical organizations [52]. The reality is that these are disability rights issues. Framing them as healthcare regulatory problems also seems less likely to stimulate reform than framing them as problems of employment discrimination against people with disabilities.

We recommend that the US EEOC adopt strict regulatory standards pertaining to workplace wellness programs in order to reduce the incidence of unwarranted medical inquiries and disability discrimination in the workplace. We also advise all professional entities to help remind members of the medical community of the ADA's rules, which protect all employees from unwarranted medical inquiries without objective evidence that the employee either:

(1) is unable to perform essential job functions due to a medical condition; or

(2) poses a high risk of substantial, imminent harm due to a medical condition [42].

While there is some variability between states in mandatory reporting requirements and due process procedures (e.g., standards of proof) for physicians regarded as impaired [53], none can truly be considered reasonable if they remain inconsistent with and do not incorporate the rules of the ADA. Finally, we believe litigation against some of these professional organizations under Title III of the ADA may be needed to discourage interference with implementation of ADA rules and regulations.

\section{Limitations}

The limitations of this study include the fact that it was not conducted on physicians, but rather on members of the general population online through MTurk. MTurk workers in full-time employment may differ in some respects from physicians, but there is little reason to believe that physicians would respond to the survey items included here in ways that are substantially different. That the survey was conducted on members of the general population should not detract from the overall findings that the descriptions are very broad and susceptible to misapplication. 
It should also be noted that while some PHPs have assigned titles to their lists of PHP descriptions (e.g., "Signs and Symptoms of Impairment," "Indicators of Impairment," and "When to Refer to Professionals Resource Network") that unequivocally designate the descriptions as indicative of impairment, most provide titles that are somewhat less overt (e.g., "Identification of the Impaired Physician," "Possible Reasons for Referrals," "Possible Signs of Impairment") (see Additional file 1). Nevertheless, these lists are highly suggestive. Though designating these descriptions as "possible" indicators of impairment may seem less objectionable, their repeated suggestion that members of one specific minority group "may" be dangerous or unsuitable for the hospital workplace is problematic. Almost anything can potentially impair one's performance, but speculative risks are not allowed under the ADA to form the basis of decisions to conduct medical inquiries of employees or refer employees for evaluations [42].

We also have no doubt that some physicians who present voluntarily to PHPs may derive benefit from the services that they receive and have known some physicians who were very grateful toward their work with a PHP. But physician impairment policies, practices, and these descriptions can be nonetheless problematic in their consideration of disabilities and the actions they will take as a result.

\section{Conclusions}

Our findings suggest that PHP descriptions of possible signs of physician impairment are very broad and may be substantially overapplied, leaving almost any physician-employee susceptible to potentially being branded as impaired. Even though the medical leaders responsible for these descriptions and associated policy might not be employers, they may still contribute to unjust work cultures and employer behaviors that discriminate against physician-employees. And to make matters worse, few physicians and health lawyers are actually aware of the provisions of the ADA, which protect all employees from unwarranted medical inquiries and evaluations [42] and supersede conflicting state laws and policies on physician impairment.

To create just cultures, as well as to possibly increase physician engagement in health resources [43, 54], reduce physician suicide [55], medical errors [4], and facilitate inclusion of qualified physicians with these conditions [5], who are not dangerous or inferior clinicians, into the workplace, AMA leaders, state medical societies, medical boards, PHPs, and other professional groups should cease disseminating and promoting these descriptions. They should amend their policies to incorporate the rules of the ADA with regard to prohibited medical inquiries and should not promote other guidance interfering with ADA rules and regulations.

\section{Additional files}

Additional file 1: Physician health program descriptions, weblinks, and additional context. (DOCX $101 \mathrm{~kb}$ )

Additional file 2: Checklist for Reporting Results of Internet E-Surveys (CHERRIES). (DOCX 23 kb)

\section{Abbreviations \\ ACGME: Accreditation Council for Graduate Medical Education; ADA: Americans with Disabilities Act; AMA: American Medical Association; CHERRIES: Checklist for Reporting Results of Internet E-Surveys; DUI: Driving under the influence; DWI: Driving while intoxicated; HIT: Human intelligence task; MTurk: Amazon's Mechanical Turk; PHP: Physician health program; SD: Standard deviation; SUD: Substance use disorder; US EEOC: US Equal Employment Opportunity Commission}

\section{Authors' contributions}

$\mathrm{NL}$ conceived the basic idea for the work with feedback from JB and collected the data. NL drafting the initial version of the manuscript, which was revised by $\mathrm{JB}$, and further developed through additional drafts. Both authors read and approved the final manuscript.

Ethics approval and consent to participate

This study was reviewed by the Institutional Review Board of Vassar College, which determined it was exempt from full review.

Consent for publication

Not applicable.

\section{Competing interests}

The authors declare they have no competing interests.

\section{Publisher's Note}

Springer Nature remains neutral with regard to jurisdictional claims in published maps and institutional affiliations.

\section{Author details}

${ }^{1}$ Georgetown University Law Center, 600 New Jersey Ave NW, Washington, DC 20001, USA. ²Department of Psychiatry, Cambridge Health Alliance/ Harvard Medical School, 26 Central St, Somerville, MA 02143, USA.

Received: 24 May 2018 Accepted: 14 August 2018

Published online: 23 August 2018

\section{References}

1. American Medical Association Policy H-95.955. Physician impairment. Revised 2009

2. American Medical Association Policy 9.3.2. Physician responsibilities to report impaired colleagues. Revised 2017.

3. Arkansas State Medical Board. Arkansas medical practices act and regulations. 2017. http://www.armedicalboard.org/professionals/pdf/mpa.pdf Accessed 18 Mar 2018.

4. Banja J. Alcohol and drug testing of health professionals following preventable adverse events: a bad idea. Am J Bioeth. 2014;14(12):25-36.

5. Lawson ND, Boyd JW. Do state physician health programs encourage referrals that violate the Americans with disabilities act? Int J Law Psychiatry. 2018:56:65-70.

6. DuBois JM, Chibnall JT, Anderson EE, Eggers M, Baldwin K, Vasher M. A mixed-method analysis of reports on 100 cases of improper prescribing of controlled substances. J Drug Issues. 2016;46(6):457-72

7. DuBois JM, Walsh HA, Chibnall JT, et al. Sexual violation of patients by physicians: a mixed-methods, exploratory analysis of 101 cases [Published online June 1, 2017]. Sex Abus doi: https://doi.org/10.1177/1079063217712217.

8. Elkin KJ, Spittal MJ, Elkin DJ, Studdert DM. Doctors disciplined for professional misconduct in Australia and New Zealand, 2000-2009. Med J Aust. 2011:194(9):452-6.

9. Khaliq AA, Dimassi H, Huang CY, Narine L, Smego RA. Disciplinary action against physicians: who is likely to get disciplined? Am J Med. 2005;118(7):773-7. 
10. Levin LC, Zozula C, Siegelman P. The questionable character of the bar's character and fitness inquiry. Law Soc Inq. 2015;40(1):51-85.

11. Morrison J, Morrison T. Psychiatrists disciplined by a state medical board. Am J Psychiatry. 2001;158(3):474-8.

12. Reid RO, Friedberg MW, Adams JL, McGlynn EA, Mehrotra A. Associations between physician characteristics and quality of care. Arch Intern Med. 2010;170(16):1442-9

13. Health Professionals' Foundation of Louisiana. Warning signs. 2017. http:// www.hpfla.org/warning-signs. Accessed 18 Mar 2018.

14. Schroeder R, Brazeau CM, Zackin F, et al. Do state medical board applications violate the Americans with disabilities act? Acad Med. 2009; 84(6):776-81.

15. Sullivan MA, Birkmayer F, Boyarsky BK, et al. Uses of coercion in addiction treatment: clinical aspects. Am J Addict. 2008;17(1):36-47.

16. Hendin H, Reynolds C, Fox D, et al. Licensing and physician mental health: problems and possibilities. J Med Licensure Discipline. 2007;93(2):6-11

17. Eysenbach $\mathrm{G}$. Improving the quality of web surveys: the checklist for reporting results of internet E-surveys (CHERRIES). J Med Internet Res. 2004;6(2):e34.

18. Chandler J, Shapiro D. Conducting clinical research using crowdsourced convenience samples. Annu Rev Clin Psychol. 2016;12:53-81.

19. Paolacci G, Chandler J. Inside the Turk: understanding mechanical Turk as a participant pool. Curr Dir Psychol Sci. 2014;23(3):184-8.

20. Shapiro DN, Chandler J, Mueller PA. Using mechanical Turk to study clinical populations. Clin Psychol Sci. 2013;1(2):213-20

21. Buhrmester M, Kwang T, Gosling SD. Amazon's mechanical Turk: a new source of inexpensive, yet high-quality, data? Perspect Psychol Sci. 2011;6(1):3-5.

22. Henderson C, Evans-Lacko S, Flach C, Thornicroft G. Responses to mental health stigma questions: the importance of social desirability and data collection method. Can J Psychiatr. 2012;57(3):152-60.

23. National Comorbidity Survey Replication. Twelve-month prevalence of DSMIV/WMH-CIDI disorders by sex and cohort. 2007. https://www.hcp.med. harvard.edu/ncs/ftpdir/NCS-R_12-month_Prevalence_Estimates.pdf. Accessed 18 Mar 2018

24. Rotenstein LS, Ramos MA, Torre M, et al. Prevalence of depression, depressive symptoms, and suicidal ideation among medical students: a systematic review and meta-analysis. JAMA. 2016;316(21):2214-36.

25. Oreskovich MR, Shanafelt T, Dyrbye $L N$, et al. The prevalence of substance use disorders in American physicians. Am J Addict. 2015;24(1):30-8.

26. Mata DA, Ramos MA, Bansal N, et al. Prevalence of depression and depressive symptoms among resident physicians a systematic review and meta-analysis. JAMA. 2015;314(22):2373-83.

27. Accreditation Council for Graduate Medical Education. Office of complaints. https://www.acgme.org/Residents-and-Fellows/Report-an-Issue/Office-ofComplaints. Accessed 18 Aug 2018.

28. Geiger SL. The ailing labor rights of medical residents: curable ill or a lost cause? U Pa J Lab Emp L. 2005;8(2):523-41.

29. Lawson ND, Kalet AL. The administrative psychiatric evaluation. J Grad Med Educ. 2016;8(1):14-7.

30. Wilkey RN. The non-negotiable employment contract: diagnosing the employment rights of medical residents. Creighton L Rev. 2011:44:705-48.

31. Benson MD, Benson JB, Stein MS. Hospital quality improvement: are peer review immunity, privilege, and confidentiality in the public interest? Nw J L Soc Pol'y. 2016;11(1):1-27.

32. Chalifoux R. So what is a sham peer review? Med Gen Med. 2005;7(4):47. https://www.ncbi.nlm.nih.gov/pmc/articles/PMC1681729/. Accessed 18 Mar 2018

33. Huntoon LR. Abuse of the "disruptive physician" clause. J Am Physicians Surg. 2004;9(3):68. http://www.jpands.org/vol9no3/huntoon.pdf. Accessed 22 Mar 2018

34. Koepke CR. Physician peer review immunity: time to euthanize a fatally flawed policy. JL Health. 2009;22(1):1-16.

35. Lauth LA. The patient safety and quality improvement act of 2005: an invitation for sham peer review in the health care setting. Ind Health $L$ Rev. 2007:4:151-72.

36. Lenzer J. Physician health programs under fire. BMJ. 2016;353:i3568.

37. Livingston EH, Harwell JD. Peer review. Am J Surgery. 2001;182(2):103-9.

38. Vyas D, Hozain AE. Clinical peer review in the United States: history, legal development and subsequent abuse. World J Gastroenterol. 2014; 20(21):6357-63

39. Boyd JW. Deciding whether to refer a colleague to a physician health program. AMA J Ethics. 2015;17(10):888-93.
40. Boyd JW. A call for national standards and oversight of state physician health programs. J Addict Med. 2015;9(6):431-2.

41. Basas CG. What's bad about wellness? What the disability rights perspective offers about the limitations of wellness. J Health Polit Policy Law. 2014;39(5):1035-66.

42. US Equal Employment Opportunity Commission. EEOC enforcement guidance on the Americans with Disabilities Act and psychiatric disabilities. https://www.eeoc.gov/policy/docs/psych.html. Published March 25, 1997. Accessed 18 Mar 2018

43. Dyrbye LN, West CP, Sinsky CA, Goeders LE, Satele DV, Shanafelt TD. Medical licensure questions and physician reluctance to seek care for mental health conditions. Mayo Clin Proc. 2017:92(10):1486-93.

44. American Medical Association. AMA officers, council members and members of the House of Delegates. 2017. https://www.ama-assn.org/sites/ default/files/media-browser/public/hod/a17-officials-members-hod.pdf. Accessed 16 Apr 2018

45. Sargent DA. The impaired physician movement: an interim report. Hosp Community Psychiatry. 1985;36(3):294-7.

46. Lawson ND, Boyd JW. Flaws in the methods and reporting of physician health program outcome studies [Published online June 1, 2018]. Gen Hosp Psychiatry. https://doi.org/10.1016/j.genhosppsych.2018.06.002.

47. Boyd JW, Knight JR. Ethical and managerial considerations regarding state physician health programs. J Addict Med. 2012;6(4):243-6.

48. Bagenstos SR. The EEOC, the ADA, and workplace wellness programs. Health Matrix. 2017;27:81-99.

49. Anderson D, Bos B, Bresler $C$, et al. A response to proposed equal employment opportunity commission regulations on employer-sponsored health, safety, and well-being initiatives. J Occup Environ Med. 2016;58(3):e103-10.

50. Blair RD, Durrance CP. Licensing health care professionals, state action and antitrust policy. lowa L Rev. 2014;100:1943-67.

51. Young MS, Alexander RK. Recognizing the nature of American medical practice: an argument for adopting federal medical licensure. DePaul J Health Care L. 2010;13(2):145-96.

52. Keville TD. Dealing with physician impairment and misconduct in the hospital medical staff setting: practical and legal issues. ABA Health eSource. 2017;13(5). https://www.americanbar.org/publications/aba_health_esource/ 2016-2017/january2017/physicianimpairment.html. Accessed 20 June 2018.

53. Federation of State Medical Boards. US medical regulatory trends and actions. 2017. https://www.fsmb.org/globalassets/advocacy/publications/usmedical-regulatory-trends-actions.pdf. Accessed 20 June 2018.

54. Arndt $\mathrm{S}$, Jones DS. Preventing sensationalistic science and fake news about substance use. Subst Abuse Treat Prev Policy. 2018;13(1):11.

55. Bourne $T$, Wynants $L$, Peters $M$, et al. The impact of complaints procedures on the welfare, health and clinical practise of 7926 doctors in the UK: a cross-sectional survey. BMJ Open. 2015;5(1):e006687.

Ready to submit your research? Choose BMC and benefit from:

- fast, convenient online submission

- thorough peer review by experienced researchers in your field

- rapid publication on acceptance

- support for research data, including large and complex data types

- gold Open Access which fosters wider collaboration and increased citations

- maximum visibility for your research: over $100 \mathrm{M}$ website views per year

At BMC, research is always in progress.

Learn more biomedcentral.com/submissions 